\title{
Clinical Profile of Neurological Manifestations Among HIV Positive Patients And Their Correlation with $\mathrm{CD}_{4}$ Count
}

\author{
${ }^{1}$ dr. Ishwar Chouhan, ${ }^{2}$ dr. Brajesh Mahawer, ${ }^{3}$ dr. Rajendra Verma, ${ }^{4}$ dr. Jasraj B. \\ Panwar ${ }^{5}$ dr. H.S. Sandhu, ${ }^{6}$ dr. S.K. Sachdeva \\ ${ }^{\text {I}}$ (All India Institute Of Medical Sciences, Jodhpur, Rajasthan, India) \\ ${ }^{2}$ (All India Institute Of Medical Sciences, Jodhpur, Rajasthan, India) \\ ${ }^{3}$ (J.L.N. Medical College, Ajmer, Rajasthan, India) \\ 4;5;6 (Govt. Medical College, Patiala, Punjab, India)
}

\begin{abstract}
:
Background \& objectives: Human immune deficiency virus (HIV) is a neurotropic virus which causes variety of neurologic manifestations either due to opportunistic infections and neoplasm or direct effects of HIV on nervous tissue. The objective of present study was to find out various neurological manifestations in HIV patients and their relation with $\mathrm{CD}_{4}$ counts.

Methods: The present study included 200 symptomatic HIV patients attending ART center at tertiary care center of north India in the time period December 2012 to October 2014 were study. Out of which 57 patients were presented with neurological complications, all study subjects were thoroughly interviewed with detailed clinical history along with general physical examination, systemic examination and detailed neurological examination.

Results: Neurological complications were seen in 57 patients out of 200 and the commonest manifestation was tubercular meningitis in $47.37 \%$ patients followed by cryptococcal meningitis in $14 \%$, HIV associated dementia in $8.80 \%$, bacterial meningitis in 7\%, progressive multifocal leucoencephalopathy in 5.30\%, peripheral neuropathy in $5.30 \%$, toxoplasmosis in $3.50 \%$, cerebrovascular accident in $3.50 \%$, cranial tuberculoma in $3.50 \%$ and acute inflammatory demyelinating polyneuropathy in $1.80 \%$ of HIV patients. $74.19 \%$ patients had $\mathrm{CD}_{4}$ count $<200 / \mathrm{mm}^{3}$ and $22.81 \%$ had $\mathrm{CD}_{4}$ count between $200-500 / \mathrm{mm}^{3}$.

Conclusion: The prevelance of neurological manifestation in HIV patients was $28.50 \%$ and opportunistic infections were the leading cause of neurological disorder. Central nervous system infections, intracranial mass lesion, stroke and HIV associated dementia were more common in patients with a $\mathrm{CD}_{4}$ count less than $200 / \mathrm{mm}^{3}$.

Key words: HIV, Neurological Manifestation, Opportunistic infection, Neuropathy, Meningitis.
\end{abstract}

\section{Introduction}

Human immunodeficiency virus is a lentivirus (a member of the retrovirus family) that causes acquired immunodeficiency syndrome (AIDS) ${ }^{[1]}$, a condition in which progressive failure of the immune system allows life-threatening opportunistic infections and cancers to thrive.

HIV infects vital cells in the human immune system such as helper $\mathrm{T}$ cells (specifically $\mathrm{CD} 4^{+} \mathrm{T}$ cells), macrophages and dendritic cells. HIV infection leads to low levels of $\mathrm{CD}^{+}{ }^{+} \mathrm{T}$-cells through three main mechanisms: First, direct viral killing of infected cells; second, increased rates of apoptosis in infected cells; and third, killing of infected $\mathrm{CD} 4^{+} \mathrm{T}$ cells by $\mathrm{CD} 8^{+}$cytotoxic lymphocytes that recognize infected cells. When $\mathrm{CD} 4^{+}$ $\mathrm{T}$ cell numbers decline below a critical level, cell-mediated immunity is lost, and the body becomes progressively more susceptible to opportunistic infections ${ }^{[2]}$. HIV is transmitted primarily by sexual contact (both heterosexual and male to male), by blood and blood products, and by infected mothers to infant intrapartum, perinatal, or via breast milk.

HIV-infected individuals can still experience a variety of neurologic abnormalities either due to opportunistic infections and neoplasms or to direct effects of HIV or its products. The main cell types that are infected in the brain in vivo are the perivascular macrophages and the microglial cells. A variety of monocytederived cytokines can contribute directly or indirectly to the neurotoxic effects in HIV infection; these include TNF-, IL-1, IL-6, TGF-, IFN-, platelet-activating factor, and endothelin ${ }^{[3]}$.

Neurologic disease is the first manifestation of symptomatic HIV infection in roughly 10-20\% of persons, while about $60 \%$ of patients with advanced HIV disease will have clinically evident neurologic dysfunction during the course of their illness ${ }^{[4,5]}$.

\section{Aims and Objectives}

1. To study the clinical profile of various neurological manifestations in HIV positive patients.

2. To study the correlation between CD4 counts and the neurological manifestations. 


\section{Materials \& Methods}

Study comprised of cross sectional study design where 200 symptomatic HIV patients attending ART center at Government medical college, Patiala, Punjab in the time period December 2012 to October 2014 were studied. Subjects fulfilling the inclusion criteria, with age more than 15 years and positive for HIV by standard NACO guidelines were included in the study after written informed consent. Patients with history of other medical and neurological illness like diabetes, alcohol and other drug abuse like narcotics, sedatives and hypnotics, cerebrovascular accidents, epilepsy and Parkinsonism,

were excluded from the study. All study subjects were thoroughly interviewed with detailed clinical history along with general physical examination, systemic examination and detailed neurological examination including higher mental function, mini-mental state examination (MMSE), sensory, motor and cranial nerve examination. Despite of routine investigations, CD4 cell count, ELISA, nerve conduction study and cerebrospinal fluid (CSF) examination were done. All patients included in study were explained about the procedure, its purpose and were assured for confidentially of the information.

\section{Results}

Present study included 200 HIV Positive patients, out of which 137 were male, 64 were female and 1 patient was male. Majority of patients were young to middle age group (26-45 year) and the mean age of HIV positive patients was $36.28 \pm 10.20$ years. Most of HIV positive patients were married (170), laborer/farmer by occupation and most common mode of transmission was sexual transmission [table 1].

The neurological manifestations present in 57 patients in which most common neurological symptoms were altered sensorium (39), headache (30), convulsion (15), focal neurological deficit (15) [table 2].

Most HIV induced neurological illness due to opportunistic was tubercular meningitis (47.37\%) followed by cryptococcal meningitis (14\%), bacterial meningitis (4\%) and primary illness were HIV associated dementia (5\%), progressive multifocal leukoencephalopathy (3\%), peripheral neuropathy (3\%) [table 3].

In our study $\mathrm{CD}_{4}$ count was done in $57(28.5 \%)$ patients in which neurological manifestations present, in 44 patients $\mathrm{CD}_{4}$ count was $<200$ and mean $\mathrm{CD}_{4}$ count was $257.50 \pm 143.61$ [table IV].

Mean $\mathrm{CD}_{4}$ count was low in HIV induced neurological illness like Progressive multifocal leucoencephalopathy (63.66 \pm 13.05$)$, Acute inflammatory demyelinating polyneuropathy (65), Toxoplasmosis $(70 \pm 22.62) \mathrm{HIV}$ associated dementia (92 \pm 31.63$)$, Cryptococcal Meningitis $(109 \pm 71.27)$, Bacterial meningitis $(110.75 \pm 57.62)$, Peripheral neuropathy $(159.33 \pm 40.21)$, Cranial tuberculoma $(165 \pm 117.37)$, Tuberculous bacterial meningitis (181.44 \pm 83.50$)$, Cerebrovascular accident $(184 \pm 96.16)$ [table 4].

Table I: Distribution of patients according to sociodemographic profile

\begin{tabular}{|l|l|}
\hline Variables & No. of patients (\%) N=200 \\
\hline Age group & $30(15 \%)$ \\
$16-25$ & $74(37 \%)$ \\
$26-35$ & $67(33.5 \%)$ \\
$36-45$ & $29(14.5 \%)$ \\
$>45$ & \\
Mean age & \\
\hline Gender & $135(67.5 \%)$ \\
Male & $64(32 \%)$ \\
Female & $1(0.5 \%)$ \\
Transgender & \\
\hline Marital status & $170(85 \%)$ \\
Married & $30(15 \%)$ \\
Unmarred & \\
\hline Mode of transmission & $163(81.5 \%)$ \\
Sexual & $21(10.5 \%)$ \\
Multiple & $16(8 \%)$ \\
Unknown & \\
\hline Occupation & $48(24 \%)$ \\
Driver/conductor & $72(36 \%)$ \\
Laborer/farmer & $33(16.5 \%)$ \\
House wife & $25(12.5 \%)$ \\
Self employed & $22(11 \%)$ \\
Student & \\
\hline
\end{tabular}

Table II: Distribution of study subjects with Neurological symptoms

\begin{tabular}{|l|l|}
\hline Neurological Symptoms & No. of patients (\%) $\mathrm{N}=57$ \\
\hline Altered Sensorium & $39(68.42 \%)$ \\
\hline Convulsions & $15(26.32 \%)$ \\
\hline Vertigo & $03(5.26 \%)$ \\
\hline FND & $15(26.32 \%)$ \\
\hline
\end{tabular}


Clinical Profile Of Neurological Manifestations Among HIV Positive Patients And Their..

\begin{tabular}{|l|l|}
\hline Cranial Nerve Abnormality & $02(3.51 \%)$ \\
\hline Sensory & $03(5.26 \%)$ \\
\hline Behavioural Abnormality & $05(8.77 \%)$ \\
\hline Headache & $30(8.77 \%)$ \\
\hline
\end{tabular}

Table III: Distribution of study subjects based on Neurologic manifestations

\begin{tabular}{|l|l|}
\hline Neurological illness & No. of patients (\%) $\mathrm{N}=57$ \\
\hline Acute inflammatory demyelinating polyneuropathy (AIDP) & $1(1.80 \%)$ \\
\hline Bacterial meningitis (BM) & $4(7 \%)$ \\
\hline Cryptococcal meningitis (CM) & $8(14 \%)$ \\
\hline Cranial tuberculoma (CTBLM) & $2(3.5 \%)$ \\
\hline Cerebrovascular accident (CVA) & $2(3.5 \%)$ \\
\hline HIV associated dementia (HAD) & $5(8.80 \%)$ \\
\hline Progressive multifocal leucoencephalopathy (PMLE) & $3(5.30 \%)$ \\
\hline Peripheral neuropathy (PN) & $3(5.30 \%)$ \\
\hline Tuberculous bacterial meningitis (TBM) & $27(47.37)$ \\
\hline Toxoplasmosis & $2(3.50 \%)$ \\
\hline
\end{tabular}

Table IV: Distribution of study subjects based on CD4 count

\begin{tabular}{|l|l|l|l|}
\hline CD $4 / \mathrm{ml}$ & Frequency & Percentage & $\mathrm{X}^{2} / \mathrm{p}$ \\
\hline$<200$ & 44 & $77.19 \%$ & $\mathrm{X}^{2}=16.86$ \\
& 13 & $22.81 \%$ & \\
\cline { 1 - 2 } Mean & $257.50 \pm 143.61$ & $\mathrm{P}=0.0001$ \\
\hline
\end{tabular}

Table V: Relation with CD4 count and neurologic illness.

\begin{tabular}{|l|l|}
\hline Illness & Mean $\mathrm{CD}_{4}$ cell count $/ \mathrm{mm}^{3}$ \\
\hline Tuberculous bacterial meningitis & $181.44 \pm 83.50$ \\
\hline Cryptococcal meningitis & $97.25 \pm 71.27$ \\
\hline Bacterial meningitis demyelinating & $110.75 \pm 57.62$ \\
\hline $\begin{array}{l}\text { Acute inflammatory } \\
\text { polyneuropathy }\end{array}$ & 65 \\
\hline Peripheral neuropathy multifocal & $63.66 \pm 13.05$ \\
\hline $\begin{array}{l}\text { Progressive } \\
\text { leucoencephalopathy }\end{array}$ & $70 \pm 22.62$ \\
\hline Toxoplasmosis & $184 \pm 96.16$ \\
\hline Cerebrovascular accident & $165 \pm 117.37$ \\
\hline Cranial tuberculoma & $92 \pm 31.63$ \\
\hline HIV associated dementia & $120.02 \pm 48.45$ \\
\hline TOTAL & \\
\hline
\end{tabular}

\section{Discussion}

In the present study, the age range of patients was from 16 to 62 years. Mean age was $36.28 \pm 10.20$ year. Majority of the patients were in the economically productive age group of $20-45$ years ${ }^{[6,7,8]}$. Out of 200 patients $135(67.5 \%)$ were male, $64(32 \%)$ were female with a male to female ratio of $2.1: 1$ and $1(0.5 \%)$ patients was transgender. $85 \%$ of patient were married where as $15 \%$ were unmarried. Predominantly sexual transmission was observed in $81.5 \%$ of patients, multiple modes of transmission were present in $21(10.5 \%)$ patients where as in $16(8 \%)$ patients the exact mode of transmission could not be ascertained. Males have commonly acquired the disease through premarital and extramarital sexual contact, whereas females have mostly acquired the disease from their spouses. Females have generally been diagnosed as HIV positive during either routine antenatal check-ups or when their husbands came with opportunistic infections. In present study most of HIV patients was laborer/farmer by occupation $72(36 \%)$ and $48(24 \%)$ patients were driver/conductor, $33(16.5 \%)$ were house wife, $25(12.5 \%)$ were self employed and $22(11 \%)$ were student ${ }^{[9,10]}$.

In our study 200 patients were included out of which 57 patients had neurological involvement and the prevalence of neurological illness was $28.5 \%$. Altered sensorium was the commonest neurological symptom seen in $39(68.42 \%)$ patients, followed by headache in $30(52.63 \%)$ patients, focal neurological deficit in 15 $(26.32 \%)$ patients and convulsion in $15(26.32 \%)$ patients of the patients ${ }^{[11,12]}$.

In present study $27(47.37 \%)$ patients had tubercular meningitis, $8(14 \%)$ had cryptococcal meningitis, 4 (7\%) had bacterial meningitis, $5(8.30 \%)$ patients had HIV associated dementia, $3(5.30 \%)$ had PMLE, and 3 (5.30\%) had peripheral neuropathy, $2(3.50 \%)$ patients were of each had intracranial tuberculoma, toxoplasmosis and CVA, $1(1.80 \%)$ patient had acute inflammatory demyelinating polyneuropathy ${ }^{[13]}$.

Among the 57 patients with neurological manifestation $44(77.19 \%)$ had $\mathrm{CD}_{4}<200 / \mathrm{mm}^{3}$ and $13(22.81 \%)$ had $\mathrm{CD}_{4}$ count $>200 / \mathrm{mm}^{3}$. The mean $\mathrm{CD}_{4}$ count was $257.50 \pm 143.61^{[14]}$.

Mean $\mathrm{CD}_{4}$ count was $181.44 \pm 83.50$ in patients with $\mathrm{TBM}$, $97.25 \pm 71.27$ for cryptococcal meningitis, $110.75 \pm 57.62$ for BM, 65 for AIDP, $159.33 \pm 40.21$ for PN, $63.66 \pm 13.05$ for PMLE, $70 \pm 22.62$ for toxoplasmosis, 
$184 \pm 96.16$ for cerebrovascular accident, $165 \pm 117.37$ for cranial tuberculoma and $92 \pm 31.63$ in patients with HIV associated dementia ${ }^{[15,16,17]}$.

\section{Conclusion}

Present study conclude that the most common neurological illness in HIV patients was tubercular meningitis followed by cryptococcal meningitis, HIV associated dementia, bacterial meningitis, progressive multifocal leucoencephalopathy, peripheral neuropathy and other illness. Neurological illness was most strongly associated with low $\mathrm{CD}_{4}$ counts. Thus, as a clinician we should focus on neurological involvement and $\mathrm{CD}_{4}$ count in HIV patients at all stages of illness to reduce morbidity and mortality in patients living with HIV.

\section{References}

[1]. Weiss RA. How does HIV cause AIDS?.Science 1993;260: 1273-9.

[2]. Cunningham, A., Donaghy, H., Harman, A., Kim, M., Turville, S. Manipulation of dendritic cell function by viruses. Current opinion in microbiology 2019;13: 524-529.

[3]. Fauci AS, Lane HC. HIV/AIDS and related disorders. In: Kasper DL, Fauci AS, Braunwald E, Hauser SL, Jameson JL, eds. Harrison's Principals of Internal Medicine, 18th ed. McGraw Hill publication. 2012;1: 1506-87.

[4]. 2010 UNAIDS. The global AIDS epidemic 2010. The Tribune. 2010 Nov 24; 5 (col.4).

[5]. Joshi PL. HIV/AIDS in India. In: Round table conference series, no.6. Ranbaxy Science Foundation, New Delhi, India. 2000;2732.

[6]. Dhadke S.V, Dhadke V.N, Mahajan N.P, Korade M.B. Clinical profile of neurological complications in HIVreactive patients and their relation with CD4. Int J Med Biomed Res 2014;3:91-100.

[7]. Patel ML, Atam V, Chaudhary SC, Gupta A. Various neurological manifestations in HIV positive patients, their outcome and its correlation with CD4 counts- A tertiary centre experience in North Indian population. Journal of AIDS and HIV Research 2012;4:198-202

[8]. Virendra C. Patil, Harsha V. Patil. Neurological manifestations of HIV-AIDS at a tertiary care center in western Maharashtra. International Journal of Medicine and Public Health 2014 ;4:210-17.

[9]. Ranga U, Shankarappa Raj, Siddappa NB. Tat protein of human immunodeficiencyvirus type 1 subtype C strain is a defective chemokine. Journal of Virology 2004;78: 2586-2590.

[10]. Sircar AR, Tripathi AK, Choudhary SK, Misra R. Clinical profile of AIDS: a study at a referral hospital. J Assoc Physicians India 1998; 46: 775-8

[11]. SK Sharma, NC Dwivedi, Nilesh Kumar, AnjuBharti, LP Meena. Neurological Manifestation of HIV Infection in North-Eastern Part of India. National Journal of Physiology, Pharmacy \& Pharmacology 2014;4: $4-8$.

[12]. Satyendra K Sonkar, Abhinav Gupta, VirendraAtam, Shyam C Chaudhary,Anil K Tripathi, and Gyanendra KSonkar. Clinical Profile of Neurological Manifestation in Human ImmunodeficiencyVirus-positive Patients. N Am J Med Sci. 2012; 4: 596-9.

[13]. Levy RM, Bredesen DE, Rosenblum ML. Neurological manifestations of the acquired immunodeficiency syndrome (AIDS): experience at UCSF and review of the literature. J Neurosurg. 1985;62:475-95.

[14]. Alaka K Deshpande and Mrinal M Patnaik. Nonopportunistic Neurologic Manifestations of the Human Immunodeficiency Virus: An Indian Study. J Int AIDS Soc. 2005; 7: 2.

[15]. Sonkar SK, Gupta A, Atam V, Chaudhary SC, Tripathi AK, Sonkar GK. Clinical profile of neurological manifestation in Humen Immunodeficiency Virus-positive patients. North Am J Med Sci 2012;4:596-9.

[16]. Gochitashvili N, Tsertsvadze T, Gatserelia L, Abashidze L, Sharvadze L. Relationship of neurological manifestations, CD4+ lymphocyte count and plasma viral load in HIV infected patients. Georgian Med News 2005;121:51-5.

[17]. Bolokadze N, Gabunia P, Ezugbaia M, Gatserelia L, Khechiashvili G. Neurological complications in patients with HIV/AIDS. Georgian Med News 2008;165:34-8. 